\section{А. В. Савченков \\ ВЛИЯНИЕ ЦЕННОСТНЫХ ОРИЕНТАЦИЙ БУДУЩИХ ПЕДАГОГОВ НА ПРОЦЕСС СТАНОВЛЕНИЯ ИХ ПРОФЕССИОНАЛЬНОЙ ГИБКОСТИ}

A. V. Savchenkov

\title{
INFLUENCE OF VALUES-BASED ORIENTATIONS OF EDUCATION STUDENTS ON EVOLVEMENT OF THEIR PROFESSIONAL FLEXIBILITY
}

\begin{abstract}
Аннотация. В статье аргументируется необходимость формирования профессиональной гибкости будущих педагогов, а также ценностного отношения к педагогической деятельности, которое лежит в ее основе. В последние годы педагогическая деятельность связана с экстремальными и стрессогенными ситуациями, с постоянно изменяющимися условиями образовательной деятельности и общими условиями неопределенности, что предъявляет требования к профессиональной гибкости будущих педагогов. От педагога, с одной стороны, требуется устойчивость его личностных качеств, с другой - гибкость, поэтому в работе рассматривается профессиональная устойчивость как фундаментальная основа. Под профессиональной гибкостью будущих педагогов понимается совокупность эмоциональной, профессиональной и поведенческой гибкости, которые обеспечивают ценностное отношение к педагогической деятельности, регуляцию и стабильность профессионального поведения, готовность быстро реагировать на меняющиеся условия и вызовы профессиональной среды посредством нахождения оригинальных способов решения профессиональных задач. Эмпирическое исследование ценностных ориентаций студентов-первокурсников проводилось на протяжении 4 лет, в исследовании приняли участие 213 студентов первого курса Южно-Уральского государственного гуманитарно-педагогического университета. В результате исследования было установлено, что студенты ориентированы на ценности, приоритетные для педагогической деятельности, и это дает основание успешности формирования ценностных ориентаций к педагогической деятельности. Сложившиеся в ходе обучения в вузе и специально организованной работы ценностные ориентации будущих педагогов постепенно трансформируются в ценностное отношение к педагогической деятельности, которое в свою очередь лежит в основе процесса становления профессиональной гибкости.

Ключевые слова: профессиональная гибкость; профессиональная устойчивость; будущий педагог; ценностные ориентации.
\end{abstract}

Abstract. There is a need to develop professional flexibility and the values-based attitude to pedagogical activity in future teachers. In recent years, pedagogical activity has been associated with extreme and stressful situations, constantly changing conditions of learning, and general uncertainty. This imposes requirements to the professional flexibility of future teachers. Teachers are required have the stability of their personal qualities, on the one hand, and flexibility, on the other hand. Therefore, this work considers professional stability as a fundamental basis. Professional flexibility of future teachers is understood as a set of emotional, vocational and behavioral flexibilities, which provide a values-based attitude to pedagogical activity, regulation and stability of professional behavior, readiness to respond quickly to changing conditions and challenges of the professional environment by finding original solutions to professional problems. An empirical study of the values-based orientations of 213 first-year students was carried out in the South Ural State Humanitarian Pedagogical University, Chelyabinsk, for four years. It was found that students are orientated towards values that are prioritized in pedagogical activity, and this provides the basis for the successful formation of the values-based orientations to pedagogical activity. In the course of university studies and specially organized work, the existing values-based orientations of future teachers are gradually transformed into a values-based attitude to pedagogical activity, which in turn underlies the evolvement of professional flexibility.

Keywords: professional flexibility; professional stability; education student; value orientation.

Сведения об авторе: Савченков Алексей Викторович, ORCID 0000-0002-7268-1533, канд. пед. наук, ЮжноУральский государственный гуманитарно-педагогический университет, г. Челябинск, Россия, alex2107@mail.ru

About the author: Savchenkov Alexey Viktorovich, ORCID 0000-0002-7268-1533, Ph.D., South Ural State Humanitarian Pedagogical University, Chelyabinsk, Russia, alex2107@mail.ru 
В последние годы педагогическая деятельность связана с противоречивыми, экстремальными, стрессогенными ситуациями, она осуществляется в динамично развивающихся, неожиданных и неоднозначных условиях. Данные факторы предъявляют к педагогу требования, с одной стороны, выполнять педагогическую деятельность стабильно, длительно и с высоким уровнем продуктивности, с другой стороны, адаптироваться к неожиданным ситуациям, использовать оригинальные способы решения возникающих проблем, обладать гибкостью поведения и эмоциональной сферы. Таким образом, от педагога требуется и устойчивость компонентов личности, и их гибкость.

Опираясь на вышесказанное, мы в своем исследовании, посвященном профессиональной гибкости будущих педагогов, рассматриваем профессиональную устойчивость как ее фундаментальную основу. При этом мы в своем исследовании рассматриваем ценностные ориентации будущих педагогов как один из компонентов профессиональной устойчивости и гибкости педагогов.

В отечественной педагогической и психологической науке проблеме профессиональной гибкости будущих педагогов внимание практически не уделяется. Профессиональная гибкость педагогов рассмотрена только в исследованиях Л.М. Митиной [5; 6], автор понимает под искомым качеством совокупность интеллектуальной, поведенческой и эмоциональной гибкости. Профессиональная гибкость педагога позволяет ему легко отказаться от несоответствующих профессиональной задаче способов поведения, вырабатывать новые и оригинальные приемы и способы поведения и эмоционального реагирования, отказаться от поведенческой ригидности и стереотипных способов поведения.

Научный поиск позволил нам выявить ряд исследований, посвященных профессиональной гибкости специалистов различных сфер. Так, Т.В. Корнилова [3] считает, что профессиональная гибкость специалистов сфер, связанных с риском и экстремальными ситуациями, обусловлена готовностью к профессиональному выбору в сложных профессиональных ситуациях и принятию ответственности за него. Т.Ю. Тодышева [8] связывает профессиональную гибкость с динамикой личностной самоорганизации и саморегуляции в профессиональной деятельности, соответственно, чем она выше, тем выше уровень сформированности профессиональной гибкости личности.

Т.А. Домбровская [1], исследуя профессиональную гибкость работников библиотечной сферы, приходит к выводу, что она является необходимым условием готовности личности к инновационным изменениям и позволяет избавиться от качеств, блокирующих профессиональное развитие (консерватизм, ригидность, косность убеждений).

Профессиональной гибкости педагогов посвящен ряд иностранных исследований.

M. Mohammadi и др. [16] связывают профессиональную гибкость педагога со способностью легко приспосабливаться к изменениям в педагогической деятельности и приспосабливать свой стиль преподавания к личностным качествам студентов. Педагоги, обладающие гибкостью, заинтересованы в решении новых инновационных задач, проявляют терпение в сложных профессиональных ситуациях.

Ряд зарубежных исследователей считают, что термин «профессиональная гибкость» является синонимом когнитивной гибкости.

По мнению M.M. Martin и R.B. Rubin [15], когнитивная гибкость определяется как осознание индивидом вариантов коммуникации, его готовность адаптироваться к новой ситуации и его самоэффективность. J.P. Dennis и J.S. VanderWall [13] определяют когнитивную гибкость как способность человека выстраивать стратегии обработки информации, чтобы противостоять новым и неожиданным ситуациям, возникающим в его окружении, в то же время указывая на то, что это навык, формирующийся в процессе обучения, то есть его можно приобрести с опытом.

Когнитивную гибкость связывают со способностью сохранять сбалансированность и гармоничность, альтернативность поведенческих реакций. Педагоги, обладающие профессиональной гибкостью, имеют более высокий уровень компетентности и навыков саморефлексии, готовы к неожиданным профессиональным ситуациям и адаптации к ним своего поведения [14]. Когнитивная гибкость становится необходимой только тогда, когда профессиональная ситуация меняется, т. е. когда ее рутинный ход неожиданно заканчивается и возникает ситуация неопределенности. Другими словами, когда человек сталкивается с проблемой, он сначала рассматривает свой опыт и думает о возможных причинах и возможных решениях для каждой причины [10]. 
В то же время, по мнению Z. Certel и др. [10], увеличение профессионального опыта педагогов приводит к снижению профессиональной гибкости. Профессиональная деятельность педагогов со временем автоматизируется и они становятся менее склонны менять свою стратегию поведения, поэтому тенденция к снижению профессиональной гибкости является негативным фактором.

Люди с высоким уровнем сформированности когнитивной гибкости склонны к проявлению положительных эмоций (общение, открытость к совершенствованию, адаптация, умение решать проблемы, коммуникативная гибкость, внимание, самоэффективность, понимание, готовность, счастье, социально-эмоциональная компетентность, критическое, творческое мышление и др.) и здоровому личностному развитию в целом и не склонны проявлять отрицательные эмоции (гнев, тревога, стресс, агрессия и др.), которые мешают профессиональному развитию [14].

Обобщая вышесказанное, отметим основные отличительные черты профессиональной гибкости педагогов:

- данный феномен в большинстве исследований рассматривается как совокупность интеллектуальной, поведенческой и эмоциональной гибкости;

- связана с выработкой новых и оригинальных поведенческих и эмоциональных реакций в профессиональных ситуациях, с отказом от поведенческой ригидности и стереотипного поведения;

- формируется с опорой на способности к самоорганизации и саморегуляции;

- зарубежными исследователями связывается с адаптивными способностями, вариативным поведением;

- большинством зарубежных исследователей рассматривается как синоним когнитивной гибкости, которая в свою очередь связана с самоэффективностью, гармоничностью и сбалансированностью поведенческих реакций.

Опираясь на исследования отечественных и зарубежных ученых, мы под профессиональной гибкостью будущих педагогов понимаем совокупность эмоциональной, профессиональной и поведенческой гибкости, которая обеспечивает ценностное отношение к педагогической деятельности, регуляцию и стабильность профессионального поведения, готовность быстро реагировать на меняющиеся условия и вызовы профессиональной среды посредством нахождения оригинальных способов решения профессиональных задач.

По нашему мнению, ценностное отношение будущих педагогов к педагогической деятельности основывается на их ценностных ориентациях. Перейдем к анализу отечественных и зарубежных исследований, посвященных данной проблематике.

Так, Л.М. Кетова [2] рассматривает ценностные ориентации будущих педагогов как сложное личностное образование, состоящее из трех компонентов: когнитивного, эмотивного и поведенческого. Это высший уровень представлений об идеалах, смысле педагогической деятельности, лежащих в основе активности и являющихся внутренним источником самоактивности и стремления к самореализации будущего педагога.

Е.А. Макарова [4] считает, что интериоризация будущими педагогами приоритетных национальных ценностей образования способствует выявлению ведущих аксиологических ориентиров образовательного процесса любой образовательной организации.

М.С. Полежаева [7] формирование ценностных ориентаций связывает с учебно-воспитательным процессом, направленным на приобретение студентами ценностей, знаний, умений и навыков образовательной деятельности, их творческое использование в своей деятельности и самовоспитание себя как разносторонней личности.

A. Chen [11] в своем исследовании доказал, что ценностные ориентации педагогов определяют успешность реализации учебных программ. По мнению R.P. Dasari [12], к ведущим ценностным ориентациям индийских педагогов относятся честность, самоконтроль, послушание, готовность к помощи, альтруизм, любовь к детям, ответственность, независимость взглядов, справедливость и дисциплина.

D. Barni, C. Russo и F. Danioni [9] выяснили, что ценностные ориентации педагогов определяют их профессиональные цели и поведение, а также стиль управления педагогическим коллективом, оказывают ведущее влияние на мотивацию и успешность обучения обучающихся. 
Таким образом, мы считаем, что ценностные ориентации составляют основу жизненной мотивации и мировоззрения будущих педагогов, определяют успешность будущей профессиональной деятельности, выступают основой для процесса формирования их профессиональной гибкости.

Эмпирическое исследование ценностных ориентаций студентов-первокурсников проводилось нами на протяжении 4 лет. В исследовании приняли участие 213 студентов (направление бакалавриат, профили «Информатика и вычислительная техника», «Транспорт», «Декоративноприкладное искусство и дизайн», «Экономика и управление») профессионально-педагогического института ФГБОУ ВО «Южно-Уральский государственный гуманитарно-педагогический университет» (г. Челябинск). Исследование проводилось с помощью разработанной авторской анкеты.

Для выявления приоритетных ценностей студентов первого курса им был задан вопрос: «Какие жизненные ценности и потребности ты считаешь наиболее важным для себя?» (табл. 1).

Таблица 1

Динамика изменений ценностных ориентаций первокурсников

\begin{tabular}{|l|c|c|c|c|c|c|c|c|c|}
\hline \multirow{2}{*}{$\begin{array}{c}\text { Ценностные ориентации } \\
\text { первокурсников }\end{array}$} & $\%$ & Ранг ответа & $\%$ & Ранг ответа & $\%$ & Ранг ответа & $\%$ & Ранг ответа \\
\cline { 2 - 9 } & $2018 / 19$ уч. г. & \multicolumn{2}{|c|}{$2017 / 18$ уч. г. } & \multicolumn{2}{|c|}{$2016 / 17$ уч. г. } & \multicolumn{2}{|c|}{$2015 / 16$ уч. г. } \\
\hline богатство & 16,7 & 10 & 6,20 & 11 & 4,8 & 10 & 13,33 & 10 \\
\hline материальное благополучие & 59,5 & 5 & 47,90 & 8 & 48,4 & 6 & 51,7 & 3 \\
\hline духовность & 57,1 & 6 & 56,20 & 5 & 56,5 & 3 & 43,3 & 6 \\
\hline развлечения & 28,6 & 9 & 25,00 & 9 & 17,7 & 9 & 28,3 & 8 \\
\hline семья & 81,0 & 1 & 81,20 & 1 & 79,0 & 1 & 78,3 & 1 \\
\hline здоровье & 81,0 & 2 & 70,80 & 2 & 58,1 & 2 & 76,6 & 2 \\
\hline карьера & 42,9 & 7 & 52,10 & 7 & 35,5 & 7 & 31,7 & 7 \\
\hline профессия & 40,5 & 8 & 31,20 & 10 & 12,9 & 8 & 18,3 & 9 \\
\hline самореализация & 61,9 & 4 & 54,20 & 6 & 53,2 & 4 & 43,3 & 6 \\
\hline дружба & 76,2 & 3 & 60,40 & 4 & 50,0 & 5 & 50 & 5 \\
\hline любовь & 76,2 & 3 & 68,80 & 3 & 50,0 & 5 & 51,7 & 4 \\
\hline
\end{tabular}

Данные таблицы 1 свидетельствуют о том, что на первых двух ранговых местах во все годы у первокурсников располагаются семья и здоровье, что говорит о стабильности их ценностных позиций и установок и должно положительно сказаться на процессе формирования их профессиональной гибкости. Установка на дружбу также остается на высокой рейтинговой позиции. Отрицательным является тот факт, что профессия во все годы находится на низких рейтинговых позициях. Это может свидетельствовать о неустойчивой мотивации к осуществлению будущей педагогической деятельности, несформированности ценностного отношения к ней; данный факт может отрицательно сказаться на процессе становления профессиональной гибкости. При этом противоречивой тенденцией является наличие на высоких рейтинговых позициях потребности в самореализации, что может свидетельствовать о направленности будущих педагогов в реализации в других видах профессиональной деятельности.

Немаловажным фактором, оказывающим влияние на формирование ценностного отношения к педагогической деятельности, является то, что на последнем месте стоит такая ценность, как богатство, т. е. для студентов гораздо больше важны гуманистические ценности.

Вторым направлением нашего исследования являлось выяснение ведущих моральнонравственных ценностей и установок, на основе которых складывается взаимоотношение будущих педагогов с другими субъектами образовательного процесса, в том числе и с обучающимися. В таблице 2 представлены приоритетные для студентов качества личности, определяющие характер их межличностных отношений.

В рейтинге личностных качеств, значимых для будущих педагогов, первые места из года в год занимают честность, уважительность, отзывчивость, доброжелательность, взаимопомощь. Данные ценности являются приоритетными для педагогической деятельности и дают основание считать, что процесс формирования ценностных ориентаций к педагогической деятельности пройдет успешно. Анализируя динамику изменения приоритетных взглядов первокурсников, отметим, что честность остается на первых ранговых местах в течение всего наблюдаемого нами периода. Данный факт является положительным, так как честность и справедливость являются значимыми качествами для будущего педагога. 
Динамика изменений приоритетных для будущих педагогов качеств личности

\begin{tabular}{|c|c|c|c|c|c|c|c|c|}
\hline \multirow{2}{*}{ Личностные качества } & $\%$ & Ранг ответа & $\%$ & Ранг ответа & $\%$ & Ранг ответа & $\%$ & Ранг ответа \\
\hline & \multicolumn{2}{|c|}{$2018 / 19$ уч. г. } & \multicolumn{2}{|c|}{ 2017/18 уч. г. } & \multicolumn{2}{|c|}{ 2016/17 уч. г. } & \multicolumn{2}{|c|}{$2015 / 16$ уч. г. } \\
\hline сотрудничество & 23,8 & 10 & 12,50 & 10 & 9,7 & 13 & 23,3 & 12 \\
\hline коллективизм & 14,3 & 11 & 14,60 & 9 & 12,9 & 12 & 26,7 & 11 \\
\hline целеустремленность & 45,2 & 7 & 50,00 & 5 & 27,4 & 11 & 31,7 & 10 \\
\hline оптимизм & 40,5 & 8 & 47,90 & 6 & 46,8 & 4 & 45 & 6 \\
\hline доброжелательность & 59,5 & 5 & 66,70 & 2 & 71,0 & 1 & 61,7 & 2 \\
\hline честность & 85,7 & 1 & 75,00 & 1 & 61,3 & 2 & 76,7 & 1 \\
\hline открытость & 45,2 & 7 & 56,20 & 4 & 41,9 & 7 & 40 & 7 \\
\hline общительность & 50,0 & 6 & 47,90 & 6 & 48,4 & 3 & 56,7 & 4 \\
\hline взаимопомощь & 64,3 & 3 & 50,00 & 5 & 37,1 & 8 & 40 & 7 \\
\hline справедливость & 40,5 & 8 & 50,00 & 5 & 37,1 & 8 & 35 & 8 \\
\hline уважительность & 66,7 & 2 & 50,00 & 5 & 43,5 & 6 & 51,7 & 5 \\
\hline терпимость & 35,7 & 9 & 41,70 & 7 & 27,4 & 9 & 33,3 & 9 \\
\hline благородство & 23,8 & 10 & 39,60 & 8 & 21,0 & 10 & 31,7 & 10 \\
\hline отзЫвчивость & 64,3 & 4 & 60,40 & 3 & 45,2 & 5 & 58,3 & 3 \\
\hline
\end{tabular}

В рамках третьего направления нашего исследования нами были выяснены личностные качества, которые, по мнению студентов, затрудняют межличностное отношение, и в том числе противоречат педагогической деятельности (табл. 3).

Таблица 3

Динамика изменений представлений будущих педагогов об отрицательных качествах личности

\begin{tabular}{|c|c|c|c|c|c|c|c|c|}
\hline \multirow{2}{*}{ Личностные качества } & $\%$ & Ранг ответа & $\%$ & Ранг ответа & $\%$ & Ранг ответа & $\%$ & Ранг ответа \\
\hline & \multicolumn{2}{|c|}{ 2018/19 уч. г. } & \multicolumn{2}{|c|}{ 2017/18 уч. г. } & \multicolumn{2}{|c|}{ 2016/17 уч. г. } & \multicolumn{2}{|c|}{ 2015/16 уч. г. } \\
\hline предательство & 95,1 & 1 & 89,60 & 1 & 45,2 & 3 & 76,7 & 1 \\
\hline жестокость & 58,5 & 3 & 58,30 & 2 & 75,8 & 1 & 55 & 2 \\
\hline цинизм & 53,7 & 4 & 43,80 & 4 & 43,5 & 4 & 46,7 & 3 \\
\hline равнодушие & 48,8 & 5 & 33,30 & 6 & 35,5 & 7 & 36,7 & 5 \\
\hline предвзятость & 34,1 & 6 & 33,30 & 6 & 25,8 & 8 & 33,3 & 7 \\
\hline эгоизм & 65,9 & 2 & 52,10 & 3 & 37,1 & 5 & 43,3 & 4 \\
\hline несправедливость & 53,7 & 4 & 58,30 & 2 & 46,8 & 2 & 35 & 6 \\
\hline пессимизм & 17,1 & 8 & 14,60 & 8 & 38,7 & 6 & 18,3 & 9 \\
\hline нетерпимость & 19,5 & 7 & 20,80 & 7 & 14,5 & 9 & 20 & 8 \\
\hline агрессивность & 58,5 & 3 & 41,70 & 5 & 14,5 & 9 & 55 & 2 \\
\hline
\end{tabular}

Ведущие ранговые позиции в течение всех лет исследования занимают такие качества, как предательство, жестокость, эгоизм и равнодушие. Способность к предательству является неприемлемым качеством для педагога, и то, что студенты именно его ставят на первый ранг, имеет огромное значения для успешности процесса формирования ценностного отношения к педагогической деятельности.

Такие качества, как жестокость, пессимизм и равнодушие, несомненно, отрицательно сказываются на процессе формирования профессиональной гибкости, поскольку делают невозможным гибкость поведенческих и эмоциональных реакций, наоборот, приводят к формированию поведенческой ригидности. То, что студенты столь высоко поставили их в рейтинге, свидетельствует об их готовности к процессу формирования профессиональной гибкости.

Подводя итоги исследования, отметим, что профессиональная гибкость выступает ключевым компонентом профессиональной компетентности педагогов в условиях неопределенности и динамически изменяющихся требований и условий образовательной среды. Ценностное отношение к педагогической деятельности составляют основу жизненной мотивации и мировоззрения будущих педагогов и является ключевым фактором, обеспечивающим результативность процесса формирования их профессиональной гибкости.

В ходе эмпирического исследования, направленного на выяснение ведущих ценностных ориентаций будущих педагогов, мы выяснили, что «семья» и «здоровье» выступают приоритет- 
ными ценностями, в то время как «профессия» находится на последних ранговых местах, что является негативным фактором для процесса формирования ценностного отношения к педагогической деятельности. Студенты ориентированы на «честность», «уважительность», «отзывчивость», «доброжелательность», «взаимопомощь», данные ценности являются приоритетными для педагогической деятельности и дают основание считать, что процесс формирования ценностных ориентаций к педагогической деятельности пройдет успешно. Среди негативных качеств личности на первые места студенты поставили «предательство», «жестокость», «эгоизм» и «равнодушие» качества, противоречащие ценностям педагогической деятельности, следовательно, будущие педагоги принимают ценности и установки педагогической деятельности.

Таким образом, у студентов сложились ценностные ориентации, которые в ходе обучения в вузе и специально организованной работе постепенно трансформируются в ценностное отношение к педагогической деятельности, которое в свою очередь лежит в основе процесса становления профессиональной гибкости.

\section{ЛИТЕРАТУРА}

1. Домбровская И. В. Профессиональная гибкость работников библиотеки как необходимое условие продвижения книги и чтения в современном обществе // Вестник Дальневосточной государственной научной библиотеки. 2007. № 2(35). С. 164-173.

2. Кетова Л. М. К вопросу о формировании ценностных ориентаций будущих педагогов в процессе изучения дисциплины «Мировая художественная культура» // Педагогическое образование в России. 2010. № 4. С. 119-124.

3. Корнилова Т. В. Принцип неопределенности в психологии выбора и риска // Психологические исследования. 2015. T. 8. № 40. URL: https://clck.ru/Px2fJ (дата обращения: 25.12.2019).

4. Макарова Е. А. Гражданско-патриотические ценности в системе ценностных ориентаций личности будущего педагога // Вестник Брянского государственного университета. 2012. № 1-2. С. 76-80.

5. Митина Л. М. Психология личностно-профессионального развития субъектов образования. М.; СПб., 2014.

6. Митина Л. М., Ефимова Н. С. Интеллектуальная гибкость учителя. Психологическое содержание, диагностика, коррекция. М., 2003.

7. Полежаева М. С. Формирование ценностных ориентаций будущих педагогов в поликультурной образовательной среде // Мир науки, культуры, образования. 2014. № 6(49). С. 139-141.

8. Тодышева Т. Ю. Личностная гибкость в профессиональной деятельности // Вестник Бурятского государственного университета. 2010. № 5(84). C. 84-88.

9. Barni D., Russo C., Danioni F. Teachers' Values as Predictors of Classroom Management Styles: A Relative Weight Analysis // Front. Psychol. 2018. V. 9:1970. https://doi.org/10.3389/fpsyg.2018.01970

10. Certel Z., Bahadır Z., Kabaca E., Seraki S. Professional experience, tolerance, empathy and reading interests as variables predicting cognitive flexibilities of physical education teachers // International Journal on New Trends in Education and Their Implications. 2018. V. 9. № 3. P. 41-51.

11. Chen A., Zhang T., Wells S. L., Schweighardt R., Ennis C.D. Impact of Teacher Value Orientations on Student Learning in Physical Education // Teaching in Physical Education. 2016. № 36(2). P. 152-161. https://doi.org/10.1123/jtpe.2016-0027

12. Dasari R.P. Value Orientation among Tribal Future Teachers of B.Ed. Programme: Need for Curricular Interventions // Universal Journal of Educational Research. 2016. № 4(6). Pp. $1432-1436$. https://doi.org/10.13189/ujer.2016.040621

13. Dennis J. P., Vander Wall J. S. The Cognitive Flexibility Inventory: Instrument Development and Estimates of Reliability and Validity // Cognitive Therapy and Research. 2010. № 34 (3). P. $241-253$. https://doi.org/10.1007/s10608-009-9276-4

14. Anderson C. M. Aggressive communication traits and their relationships with the cognitive flexibility scale and the communication flexibility scale // Journal of Social Behavior and Personality. 1998. V. 13. № 3. P. 531-540.

15. Martin M. M., Rubin R. B. A new measure of cognitive flexibility // Psychological reports. 1995. № 76. P. 623-626. https://doi.org/10.2466/pr0.1995.76.2.623

16. Mohammadi M., Ahmadipour N., Kouhdasht R.N., Bordbar N. Flexibility of Iranian Teachers Teaching Methods and High School Students' Gains // Modern Applied Science. 2016. V. 10. № 10. P. 48-54. http://dx.doi.org/10.5539/mas.v10n10p48 


\section{REFERENCES}

1. Dombrovskaya, I. V. (2007). Professional'naya gibkost' rabotnikov biblioteki kak neobkhodimoe uslovie prodvizheniya knigi i chteniya v sovremennom obshchestve. Vestnik Dal'nevostochnoi gosudarstvennoi nauchnoi biblioteki, (2(35)), 164-173. (In Russian).

2. Ketova, L. M. (2010). To the question of forming value orientations of future teachers in the process of studying "World art culture". Pedagogical education in Russia, (4), 119-124. (In Russian).

3. Kornilov, V. T. (2015). The principle of uncertainty in psychology of choice and risk. Psikhologicheskie Issledovaniya al research, (8(40)) 3-3. (In Russian).

4. Makarova, E. A. (2012). Civil and patriotic values in system valuable orientations of the identity of future teacher. The Bryansk State University Herald, (1-2), 76-80. (In Russian).

5. Mitina, L. M. (2014). Psikhologiya lichnostno-professional'nogo razvitiya sub'ektov obrazovaniya. Moscow; St. Petersburg. (In Russian).

6. Mitina, L. M., \& Efimova, N. S. (2003). Intellektual'naya gibkost' uchitelya. Psikhologicheskoe soderzhanie, diagnostika, korrektsiya. Moscow. (In Russian).

7. Polezhaeva, M. S. (2014). The formation of value orientations of future teachers in a multicultural educational environment. Mir nauki, kultury, obrazovaniya, (6(49)), 139-141. (In Russian).

8. Todysheva T. Yu. (2010). Personal flexibility in the professional activity of managers. Vestnik Buryatskogo gosudarstvennogo universiteta, (5(84)), 84-88. (In Russian).

9. Barni, D., Russo, C., \& Danioni, F. (2018). Teachers' Values as Predictors of Classroom Management Styles: A Relative Weight Analysis. Front. Psychol, (9). https://doi.org/10.3389/fpsyg.2018.01970

10. Certel, Z., Bahadır, Z., Kabaca, E., \& Seraki, S. (2018). Professional experience, tolerance, empathy and reading interests as variables predicting cognitive flexibilities of physical education teachers. International Journal on New Trends in Education and Their Implications, (9(3), 41-51.

11. Chen, A., Zhang, T., Wells, S. L., Schweighardt, R., \& Ennis, C. D. (2016). Impact of Teacher Value Orientations on Student Learning in Physical Education. Teaching in Physical Education, 36(2), $152-161$. https://doi.org/10.1123/jtpe.2016-0027

12. Dasari, R. P. (2016). Value Orientation among Tribal Future Teachers of B.Ed. Programme: Need for Curricular Interventions. Universal Journal of Educational Research, (4(6)), $1432-1436$. https://doi.org/10.13189/ujer.2016.040621

13. Dennis, J. P., \& Vander, Wall J. S. (2010). The Cognitive Flexibility Inventory: Instrument Development and Estimates of Reliability and Validity. Cognitive Therapy and Research, (34(3)), $241-253$. https://doi.org/10.1007/s10608-009-9276-4

14. Anderson, C. M. (1998). Aggressive communication traits and their relationships with the cognitive flexibility scale and the communication flexibility scale. Journal of Social Behavior and Personality, 13(3), 531540.

15. Martin, M. M., \& Rubin, R. B. (1995). A new measure of cognitive flexibility. Psychological reports, (76), P. 623-626. https://doi.org/10.2466/pr0.1995.76.2.623

16. Mohammadi, M., Ahmadipour, N., Kouhdasht, R. N., \& Bordbar, N. (2016). Flexibility of Iranian Teachers Teaching Methods and High School Students' Gains. Modern Applied Science, (10(10)), 48-54. https://doi.org/10.5539/mas.v10n10p48

Савченков А. В. Влияние ценностных ориентаций будущих педагогов на процесс становления их профессиональной гибкости // Вестник Нижневартовского государственного университета. 2020. № 3. С. $79-85$. https://doi.org/10.36906/2311-4444/20-3/12

Savchenkov, A. V. (2020). Influence of values-based orientations of education students on evolvement of their professional flexibility. Bulletin of Nizhnevartovsk State University, (3). 79-85. (In Russian). https://doi.org/10.36906/23114444/20-3/12 